\title{
Effect of acid production by Penicillium oxalicum on physicochemical properties of bauxite residue
}

by Zhang, Y., Xue, R., He, X., Cheng, Q., Hartley, W. and Xue, $S$

Copyright, publisher and additional information: .This is the authors' accepted manuscript. The published version is available via Taylor \& Francis Online Please refer to any applicable terms of use of the publisher

DOI link to the version of record on the publisher's site

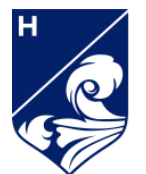

Harper Adams

University 
4 Yifan Zhang ${ }^{\mathrm{a}}$, Rui Xue ${ }^{\mathrm{b}}$, Xuan $\mathrm{He}^{\mathrm{a}}$, Qingyu Cheng, William Hartley ${ }^{\mathrm{c}}$,

5 Shengguo Xue ${ }^{\mathrm{a}, *}$

6

\section{Effect of acid production by Penicillium oxalicum on physicochemical} properties of bauxite residue

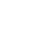

${ }^{a}$ School of Metallurgy and Environment, Central South University, 932 Lushan South Road, Changsha, Hunan, 410083, PR China

${ }^{b}$ College of Environmental Sciences, Sichuan Agricultural University, Chengdu 611130, P.R. China

${ }^{c}$ Crop and Environment Sciences Department, Harper Adams University, Newport, Shropshire, TF10 8NB, United Kingdom

\#Address correspondence to Shengguo Xue; E-mail address:sgxue@csu.edu.cn.

*Present address: School of Metallurgy and Environment, Central South University

(CSU), Changsha 410083, PR China 
ABSTRACT Large-scale discharge of bauxite residue, an alkaline, saline and nutrientdeficient waste material produced in the process of alumina production, has created extreme environments that are challenging to restore. Microbial pathways are found to play a critical role in the rehabilitation of these residues. In this study, Penicillium oxalicum, an alkaliresistant acid-producing fungus screened from bauxite residue disposal sites, was used to examine its effectiveness for restoration of bauxite residue. By comparing different biomass pretreatment methods, steam explosion pretreatment biomass was added to the medium to enhance microbial metabolism, through production of organic acids and various enzymes. $P$. oxalicum mainly secreted oxalic acid, formic acid and acetic acid. Addition of pretreatment biomass and microbes significantly lowered bauxite residue $\mathrm{pH}$, whilst increasing $\mathrm{EC}$ and enzyme activity. Furthermore, the metabolic process of this fungus may promote the release of basic ions dominated by $\mathrm{Na}^{+}$and increase soluble cations. This study provides an experimental demonstration of bioremediation in bauxite residue, and enables future large-scale simulation of vegetation establishment on bauxite residue disposal areas.

KEYWORDS Bauxite residue; Penicillium oxalicum; Biomass pretreatment; Organic acid; bioremediation 


\section{Introduction}

Extreme harsh environments are characterized by combinations of variables, such as high or low temperature, high pressure, drying, high alkalinity or salinity, high acidity, high-intensity ultraviolet (UV) radiation, and poor nutrients (Kaur et al., 2019; Yin et al., 2019). Microorganisms surviving optimally under extreme conditions are considered to be extremophiles, first proposed by Macelroy (1974), whereas those that have special physiological functions are described as functional microorganisms. They form a specific metabolic mechanism in the process of adapting to extreme environments (Sayed et al., 2020). The study of functional microbes is of great significance to understand the ecological functions and biogeochemical cycles of elements in extreme conditions (Chen et al., 2018).

Bauxite residue is a waste material generated from the Bayer process used for alumina refining. It has extremely high alkalinity, salinity, exchangeable sodium percentage (ESP), and fine particle size (Santini et al., 2015). Bauxite residue occupies large land resources and forms an extreme harsh environment, where its $\mathrm{pH}$ is likely to cause alkalization of groundwater at the disposal site or the surrounding areas (Jones and Haynes, 2011). The effective restoration of this waste material is therefore of great importance. Previous studies have reported that controlling alkalinity of bauxite residue is key to improving its physical and chemical properties and thus converting it to arable land (Gräfe and Klauber, 2011). A number of methods can be used for bauxite residue restoration, including inorganic acid neutralization (Xue et al., 2016), carbonization, 
gypsum modification, seawater neutralization, and bioremediation. Borra et al. (2015) applied seawater and mineral acids (e.g., $\mathrm{HCl}, \mathrm{HNO}_{3}$ or $\left.\mathrm{H}_{2} \mathrm{SO}_{4}\right)$ to neutralize the residue, but this was not considered in the eco-engineering scope due to the high costs. In combination with $\mathrm{CaSO}_{4}$, organic matter (OM) (i.e., sugarcane mulch, Lucerne hay) significantly lowered porewater $\mathrm{pH}$ from 11.4 to 9.0 in the bauxite residue (You et al., 2019). Microbial activity contributed to $\mathrm{pH}$ neutralization in acidic waste material and this is also likely to be the case for alkaline bauxite residue (Santini et al., 2015). Among these neutralization methods, bioremediation through functional microorganisms has received much attention. Microbial restoration may be accomplished by metabolic processes, such as organic and inorganic acids and carbon dioxide production. However, limited research has been reported about the action of functional microorganisms on bauxite residue restoration. Specifically, elucidation of the mechanisms of microbial action on alkaline regulation of bauxite residue which is urgently needed.

Courtney et al., used organic matter to enhance microbial activity in bauxite residue, with its alkalinity decreasing from 13.0 to 7.0 (Courtney et al., 2013). Microorganisms may metabolize acidic substances through various pathways to dissolve a large amount of binding alkali, thereby reducing its alkalinity and salinity. Santini et al. investigated the influence of microorganisms on the alkalinity of bauxite residue and found that microorganisms can secrete organic acids through glucose metabolism, thereby reducing the $\mathrm{pH}$ from 9.5 to 6.5 (Santini et al., 2016). Bulk storage of bauxite residue provides an anaerobic environment for microorganisms, enabling 
them to metabolize organic acid. Organic acid is a common product after decomposition of organic matter and is due to the ability of some microorganisms to decompose simple organic nutrients and natural polymers, such as cellulose, lignin, and humus (Mesbah et al., 2012); fungal genera such as trichoderma, fusarium, penicillium, aspergillus, mucor, and botrytis have all been shown to decompose cellulose (Adsul et al., 2007). Organic wastes like hay or wood chips have also been used to replace glucose for microorganisms to produce organic acids, thereby neutralizing bauxite residue $\mathrm{pH}$ (Salomskiene et al., 2019).

Penicillium oxalicum has been screened from bauxite residue, revealing both alkali-tolerance and acid production (Liao et al., 2018). P. oxalicum has been observed to decrease $\mathrm{pH}$ to 3.6 after 5 days of culture, producing approximately 4000 $\mathrm{mg} / \mathrm{L}$ of organic acids (Li et al., 2016). P. oxalicum was also shown to enhance the degradation efficiency of lignocellulosic materials (Du et al., 2017). P. oxalicum has a relatively complete cellulase production enzyme system and can degrade cellulose into small molecules of sugar for its own growth and metabolism, while producing energy. However, the effect of this functional fungus on bauxite residue restoration remains unclear and requires further investigation. In addition, the remediation process of bauxite residue be closely correlated with the change of enzyme activity. The soil enzymes are one of the most active organic components in soil, and promote the metabolic process of soil (Whiffin et al., 2007). 
102

103

104

105

Cellulase, urease, protease, phosphatase and other enzymes are widely found in soil. Therefore, the assessment of soil enzyme should be taken into account for remediation of bauxite residue.

Giving that $P$. oxalicum can secrete organic acids and decompose biomass, it was used in this study for the alkaline regulation of bauxite residue. Organic wastes (bagasse and bran) was used as a carbon source from the practical operation point of view. The difference in acid production by microorganism under different biomass pretreatment methods was examined. The results provide a new approach for the restoration of bauxite residue and converting it to arable land.

\section{Materials and methods}

\section{Collection of samples}

In July 2016, fresh bauxite residue samples ( $<3$ years) were collected from a bauxite residue disposal site in Guangxi province $\left(108^{\circ} 18^{\prime} \sim 107^{\circ} 53^{\prime} \mathrm{E}, 23^{\circ} 12^{\prime} \sim 23^{\circ} 54^{\prime} \mathrm{N}\right)$, while biomass (bagasse and bran) samples were obtained from a local sugar refinery. The average annual rainfall and temperature in the sample collection region were $1359 \pm 50$ $\mathrm{mm}$ and $11-17{ }^{\circ} \mathrm{C}$, respectively, which is typically subtropical. The collected samples were air dried and ground, and passed through a $2.0 \mathrm{~mm}$ sieve. The samples were then placed in sealed bags for later use. Physicochemical properties were as follows; $\mathrm{pH}$ 10.43, EC $2.11 \mathrm{mS} / \mathrm{cm}$, ESP $58.89 \%$, CEC $339.49 \mathrm{cmol} / \mathrm{kg}$, and exchangeable $\mathrm{Na}$ concentration $2.07 \times 10^{3} \mathrm{~g} / \mathrm{kg}$, respectively (Tian et al., 2019). 
123 Steam explosion pretreatment, acid pretreatment, alkaline pretreatment and hydrogen 124 peroxide pretreatment were adopted for biomass (bagasse:bran $=2: 1$ ) pretreatment. The 125 pretreatment process was carried out according to Kumar et al., (2009). Before 126 pretreatment, bagasse and bran were crushed by a pulverizer, and then passed through 127 a $0.25 \mathrm{~mm}$ nylon sieve. During the steam explosion pretreatment, biomass was 128 autoclaved at $180{ }^{\circ} \mathrm{C}$, after which the pressure was released suddenly. For acid 129 pretreatment, $1 \%(\mathrm{w} / \mathrm{w}) \mathrm{H}_{2} \mathrm{SO}_{4}$ solution was mixed with biomass then treated with high130 pressure steam at $121^{\circ} \mathrm{C}$ for 1 hour. For alkali pretreatment, each gram of biomass was 131 mixed with $0.075 \mathrm{~g}$ calcium hydroxide, and the mixture was heated for $4 \mathrm{~h}$ at $120{ }^{\circ} \mathrm{C}$. 132 During hydrogen peroxide pretreatment, 5\% (w/w) $\mathrm{H}_{2} \mathrm{O}_{2}$ solution was mixed with 133 biomass and treated at $30{ }^{\circ} \mathrm{C}$ for $24 \mathrm{~h}$ in a water bath shaker. The solid-to-liquid ratio 134 of each method was 1:10. Biomass medium was prepared by mixing the treated biomass with distilled water. 136 A freeze-preserved strain of Penicillium oxalicum, EEEL01, was inoculated into the 137 medium and a blank control was used without inoculation. The $\mathrm{pH}$ which revealed acidproduction capacity, was determined after 9 days of incubation in a shaker at $28^{\circ} \mathrm{C}$ at $139160 \mathrm{r} / \mathrm{min}$. The acid-producing effects of $P$. oxalicum under different methods were compared to select an optimal biomass pretreatment method. 


\section{Analysis of organic acids by HPLC}

P. oxalicum was inoculated into a glucose medium (glucose $1.0 \mathrm{~g}$, peptone $0.5 \mathrm{~g}, \mathrm{NaCl}$ concentration $0.8 \%$, initial $\mathrm{pH} 9.0$, distilled water $50 \mathrm{~mL}$, abbreviated as $\mathrm{GM}$ ) and a biomass medium (bagasse $1.0 \mathrm{~g}$, bran $0.5 \mathrm{~g}$, distilled water $50 \mathrm{~mL}$, abbreviated as $\mathrm{BM}$ ), respectively. The medium was cultivated in a shaker at $28^{\circ} \mathrm{C}$ for 7 days at $160 \mathrm{r} / \mathrm{min}$, and the filtrate of the medium was then analyzed by high performance liquid chromatography (HPLC).

Standards and samples were analysed using a Hypersil C18 chromatographic column $(250 \mathrm{~mm} \times 4.6 \mathrm{~mm}$ id, $5 \mathrm{~m})$, and $0.2 \% \mathrm{H}_{3} \mathrm{PO}_{4}$ buffer $(\mathrm{pH}=2.6)$ as the mobile phase. The injection volume was set to $10 \mu \mathrm{l}$ and the column oven temperature to $25^{\circ} \mathrm{C}$. The UV detection wavelength and gradient elution flow rate were $210 \mathrm{~nm}$ and 0.5 $\mathrm{mL} / \mathrm{min}$, respectively. The standard single organic acid solution $(2 \mathrm{mg} / \mathrm{mL})$ and standard mixed organic acid solution (including oxalic acid, formic acid, malic acid, acetic acid, citric acid, propionic acid, butyric acid and pentanoic acid) were filtered by a $0.22 \mathrm{~m}$ filtration membrane, and the peak sequence and time of elution of the various organic acids was determined by HPLC.

The fermentation broth of the glucose medium (GM) and biomass medium (BM) were collected. For preliminary filtration, $80 \mu \mathrm{m}$ filter paper was used to remove the bacteria. An appropriate amount of filtrate was taken and centrifuged at $10000 \mathrm{rpm}$ for $10 \mathrm{~min}$. The supernatant was mixed with acetonitrile solution at a ratio of $1: 3$ and placed in the sample bottle. Organic acids in the samples were analysed by HPLC. The 
concentration of samples was calculated to determine the content of organic acids:

$$
C x=C r \times(A x / A r) \times 100 \%
$$

\footnotetext{
Where $\mathrm{Cx}$ is the sample solution concentration, $\mathrm{Cr}$ is the standard solution concentration, Ax is the sample solution peak area, and Ar is the standard solution peak area.
}

\section{Neutralization of bauxite residue}

The experiment was replicated three times and included three groups, 1) $500 \mathrm{~g}$ of bauxite residue and $50 \mathrm{~g}$ of biomass (bagasse:bran $=2: 1$ ) mixed in a plastic container and inoculated with $P$. oxalicum regularly (once every 5 days, abbreviated as RF, 2) 500 $\mathrm{g}$ of bauxite residue and inoculated with P. oxalicum regularly, named as BF, 3) $500 \mathrm{~g}$ of bauxite residue without any treatment, abbreviated as CK. Bauxite residue was airdried to a constant weight after the 6th, 12th, 18th, 24th, 30th and 36th day. Bauxite residue $(5 \mathrm{~g})$ was mixed with $50 \mathrm{~mL}$ of distilled water, and then filtered to obtain the supernatant for determiing $\mathrm{pH}, \mathrm{EC}$ and soluble $\mathrm{Na}^{+}, \mathrm{K}^{+}, \mathrm{Ca}^{2+}$ and $\mathrm{Mg}^{2+}$ concentrations (ICP-AES, Optima 5300DV, American Perkin Elmer company) every 6 days. The urease content in bauxite residue was determined by Qin et al., (2010), and the cellulase content was determined by 3, 5-dinitrosalicylic acid assay (Nannipieri et al., 2012). 
182

183

184

\section{Data analysis}

SPSS 19.0 was used for data analysis, and Origin 8.0 for data fitting and image processing. ANOVA was used to analyze changes in bauxite residue properties under different treatments. Near-side X-ray absorption spectroscopy (NEXAFS) analysis was performed on a BL08U1A beamline at the Shanghai Synchrotron Radiation Facility (SSRF, Shanghai, China).

\section{Results and discussion}

\section{Optimum biomass pretreatment}

Figure 1 reveals $\mathrm{pH}$ changes after 9 days of inoculation with $P$. oxalicum in the medium. In comparison with $\mathrm{CK}$ treatments, $\mathrm{pH}$ decreased significantly after steam explosion pretreatment and acid treatment, while no significant changes could be found for $\mathrm{pH}$ in BM following alkaline or hydrogen peroxide pretreatments. This indicated that $P$. oxalicum had a relatively strong capacity to produce acid by the first two pretreatments which enabled them to use bagasse and bran for spontaneous growth and metabolism. However, in the acid pretreatment, toxicity, corrosiveness of equipment, recovery of acid, and the production of fermentation inhibitors such as furan-type inhibitors, prevented widespread application of this method. By contrast, steam explosion pretreatment hydrolyzed hemicellulose, transformed lignin at high temperature, and 
205

improved the efficiency of microbial metabolism using biomass (Haghighi Mood et al., 2013). Therefore, steam explosion pretreatment was used as an optimal method to pretreat biomass in the following experiments.

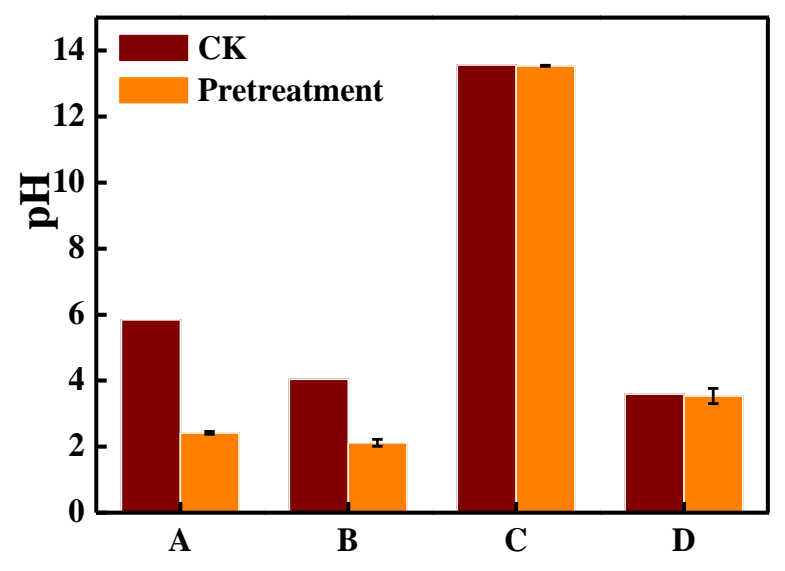

Figure 1 Comparison of $\mathrm{pH}$ in biomass medium with different pretreatments (A: Steam explosion pretreatment; B: Acid pretreatment; C: Alkaline pretreatment; D: Hydrogen peroxide pretreatment)

\section{Acid production by fermentation}

Pure compounds of different acids were used as standards to identify components. By injecting standard solutions and comparing retention times, it was possible to identify organic acids types. The type of organic acid used as standard was selected based on the acids reported in $P$. oxalicum, therefore, formic acid, malic acid, acetic acid, citric acid, propionic acid, oxalic acid, butyric acid and valeric acid were selected. Table 1 
217 acid, butyric acid and valeric acid were approximately $3.522 \mathrm{~min}, 3.849 \mathrm{~min}, 4.191 \mathrm{~min}$,

$2184.330 \mathrm{~min}, 4.885 \mathrm{~min}, 14.10 \mathrm{~min}, 19.62 \mathrm{~min}$, and $25.60 \mathrm{~min}$ respectively, which is 219 consistent with the peak sequence of organic acids reported in other studies (Krishna et 220 al., 2005).

Table 1 HPLC data for organic acids

\begin{tabular}{cccccc}
\hline & Molecular & Retention time & Peak area & Peak & Solution \\
Types of acid & formula & $(\mathrm{min})$ & $(\mathrm{mAU})$ & height & $\begin{array}{c}\text { concentration } \\
(\mathrm{mg} / \mathrm{mL})\end{array}$ \\
\hline oxalic acid & $\mathrm{C}_{2} \mathrm{H}_{2} \mathrm{O}_{4}$ & 3.522 & 8011809 & 514182 & 8.88 \\
formic acid & $\mathrm{CH}_{2} \mathrm{O}_{2}$ & 3.849 & 1841116 & 233993 & 2.10 \\
malic acid & $\mathrm{C}_{4} \mathrm{H}_{6} \mathrm{O}_{5}$ & 4.191 & 276017 & 26464 & 10.01 \\
acetic acid & $\mathrm{C}_{2} \mathrm{H}_{4} \mathrm{O}_{2}$ & 4.330 & 973983 & 183686 & 1.93 \\
citric acid & $\mathrm{C}_{6} \mathrm{H}_{8} \mathrm{O}_{7}$ & 4.885 & 532011 & 82843 & 10.02 \\
propionic acid & $\mathrm{C}_{3} \mathrm{H}_{6} \mathrm{O}_{2}$ & 14.10 & 2267036 & 129292 & 1.99 \\
butyric acid & $\mathrm{C}_{4} \mathrm{H}_{8} \mathrm{O}_{2}$ & 19.62 & 1501711 & 137017 & 2.05 \\
valeric acid & $\mathrm{C}_{5} \mathrm{H}_{10} \mathrm{O}_{2}$ & 25.60 & 919513 & 80843 & \\
\hline
\end{tabular}

After 7 days of culture, chromatographic analysis of the organic acids in GM and

224 BM were obtained (Figure 2). Components with retention times of $3.51 \mathrm{~min}, 3.83 \mathrm{~min}$,

2254.30 min are the main compositions in the medium due to height and surface area. By comparing the data presented in Table 1 for pure compounds with the results presented 
227

228

229

230

231

in Figure 2, under both culture conditions, P. oxalicum could secrete different concentrations of oxalic acid, formic acid and acetic acid, accompanied by the production of some secondary metabolites. Studies have shown that this fungus can metabolize organic acids dominated by oxalic acid, and the types and content of acid are strongly related to carbon, nitrogen and phosphorus sources (Peng et al., 2017). The carbon and nitrogen source have much more effect on the secretion of organic acids by P. oxalicum than phosphorus. Gong and co-workers found that the nitrogen source could directly affect the pathway of acid production of $P$. oxalicum, and it mainly secreted malic acid, acetic acid, propionic acid, citric acid and succinic acid when ammonium nitrogen was provided (Gong et al., 2014).

When using pretreatment biomass as a carbon source for the growth and metabolism of $P$. oxalicum, oxalic acid, formic acid and acetic acid secreted were 0.12 $\mathrm{mg} / \mathrm{mL}, 0.51 \mathrm{mg} / \mathrm{mL}$ and $0.31 \mathrm{mg} / \mathrm{mL}$, respectively. The production of organic acids is directly related to the reduction of the medium $\mathrm{pH}$ and provides a basis for its subsequent use in neutralizing alkali in bauxite residue. In this study, the content of acetic acid produced by P. oxalicum in either GM or BM was relatively high. These results indicate that this functional fungus has the capacity to metabolize acid by using pretreated biomass as a carbon source. In addition, pretreated biomass instead of glucose for the growth of $P$. oxalicum can greatly reduce the practical application cost. Its acid production capacity is related to the molecular structure of carbon and nitrogen sources. In this study, the molecular structure of bagasse and bran is relatively complex. 
249 small molecular substances so as to provide for its own growth and acid production 250 (Roberts et al., 2015).

252 the standards. It can be assumed that $P$. oxalicum can also metabolize other acidic 253 substances. This functional fungus can produce secondary metabolites (such as 254 secalonic acid A), and the unknown components in Figure 2 may be secondary 255 metabolites (Wang et al., 2013). They were not components of interest, and further 256 studies are required to identify these compounds that are beyond the scope of this study.
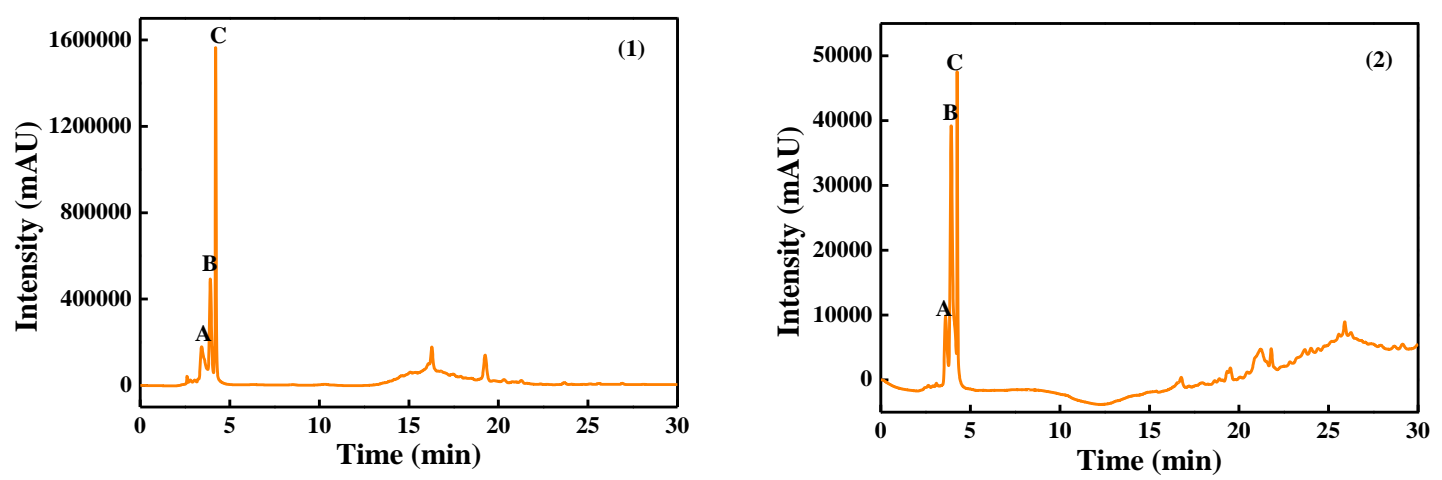
acid, C-acetic acid) as determined by HPLC. 
Inoculation of $P$. oxalicum had little effect on enzyme activity in bauxite residue, while enzyme activity increased with extension of culture time under the addition of biomass. This illustrates that biomaterial addition leads to the increase of enzyme activity, which is consistent with former experimental results in our laboratory (Liao et al., 2019). Urease activity and cellulose enzymes were below detection limits of RF and CK and not shown in Figure 3. Cellulase activity in bauxite residue significantly increased after 24 days, and reached the maximum value $(0.19 \mathrm{~g} / \mathrm{kg})$ after 36 days of culture (Figure 3). Urease activity determined the conversion efficiency of organic nitrogen to available nitrogen and the supply level of inorganic nitrogen in the soil, which mainly comes 271 from microorganisms and plants (Roscoe et al., 2000). Urease activity in bauxite residue increases with the extension of culture time, but the activity was not high. P. oxalicum can degrade biomaterial and promote carbon cycles because of its high cellulase production ability. Cellulase production from sugarcane bagasse pretreatments and pure synthetic substrates has been studied showing that optimal 276 cellulase enzyme production was at $\mathrm{pH} 4.9$ and between 52 to $58^{\circ} \mathrm{C}$ (de Castro et al., 277 2010). It has also been shown that CMC enzyme activity may reach $31.12 \mathrm{IU} / \mathrm{mL}$ under optimal enzyme production conditions (Tao et al., 2011). However, the high alkaline environment of bauxite residue in this study restricts the growth and metabolism of microorganisms, therefore having an effect on enzyme activity. 

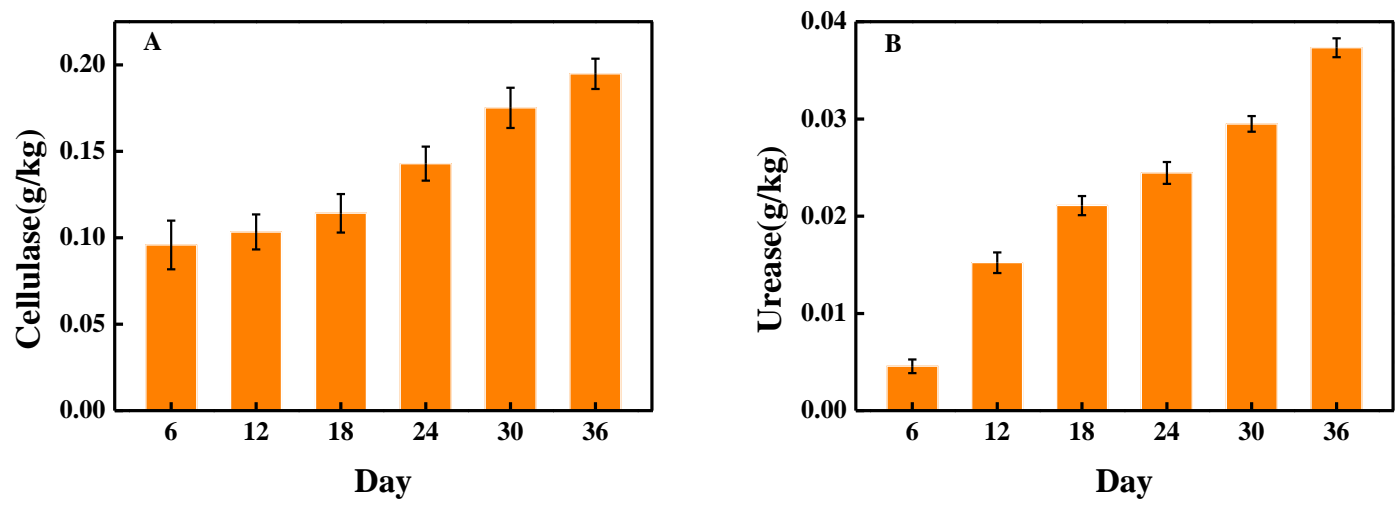

Figure 3 Cellulase (A) and urease (B) activities in bauxite residue. oxalicum and pretreatment biomass can significantly reduce bauxite residue alkalinity. During 6 to 12 days of culture, bauxite residue $\mathrm{pH}$ declined significantly. This may be due to acid production in the early stages of culture being neutralized by free alkali. In the latter period, alkali was slightly released, maintaining the acid-base balance in the whole culture system, so $\mathrm{pH}$ decreased slowly. Khaitan believed that the alkaline

292 dissolution process of bauxite residue required at least 50 days to reach the chemical equilibrium under laboratory conditions (Khaitan et al., 2009). Although the pH of bauxite residue may be reduced by microorganisms, the addition of biomass can lower 

for it to continuously produce organic acids, thereby neutralizing more alkaline 297 substances in the residue. It has also been revealed that microorganisms can metabolize 298 acid and reduce the $\mathrm{pH}$ at the initial stage of growth in alkaline and saline environments 299 (bauxite residue), but the $\mathrm{pH}$ was shown to rise when the microorganisms entered their 300 decline phase (Qu et al., 2013). After 18 days of cultivation with biomass, EC was stable at approximately $2.18 \mathrm{~ms} / \mathrm{cm}$, which was greater than that of microbe action alone in the whole culture process; increase in EC has been shown to be related to the dissolution of basic ions in bauxite residue (Kong et al., 2017). Other investigations have shown that EC increased with time, probably due to accelerated hydrolysis of sodium-rich minerals in the residue.
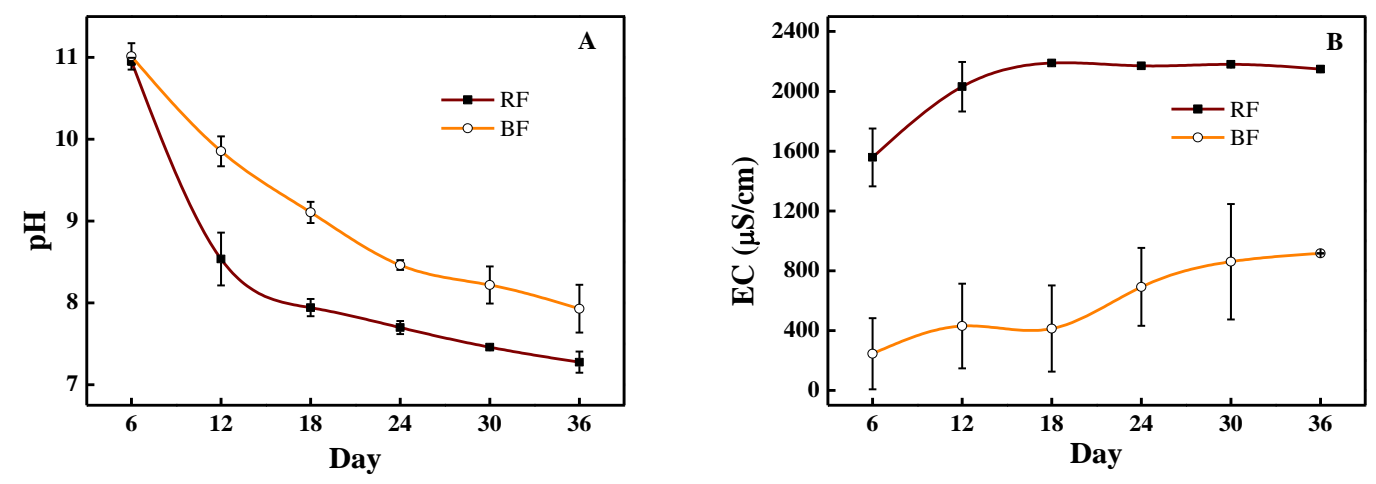

an increase in EC (Figure 5). Studies had shown that soluble $\mathrm{Na}^{+}$content represented

312 the concentration of Na buffer substances in bauxite residue (Kong et al., 2017). The

313 metabolic process of $P$. oxalicum may promote the release of metal ions dominated by

$314 \mathrm{Na}^{+}$and increase the content of soluble cations. With the addition of biomass and fungus,

315 the content of $\mathrm{Ca}^{2+}$ in bauxite residue increased slowly after 24 days of cultivation,

316 while $\mathrm{K}^{+}$and $\mathrm{Mg}^{2+}$ showed no significant changes. Soluble $\mathrm{Na}^{+}$increased when $P$.

317 oxalicum acted alone in bauxite residue, but the amendment effect on $\mathrm{K}^{+}, \mathrm{Ca}^{2+}$ and

$318 \mathrm{Mg}^{2+}$ was not obvious during the whole culture process. It was observed that the

319 addition of biomass in bauxite residue significantly improved the soluble cation content, 320 and $\mathrm{Na}^{+}$content in the supernatant of bauxite residue increased by one-fold (Kong et 321 al., 2018).
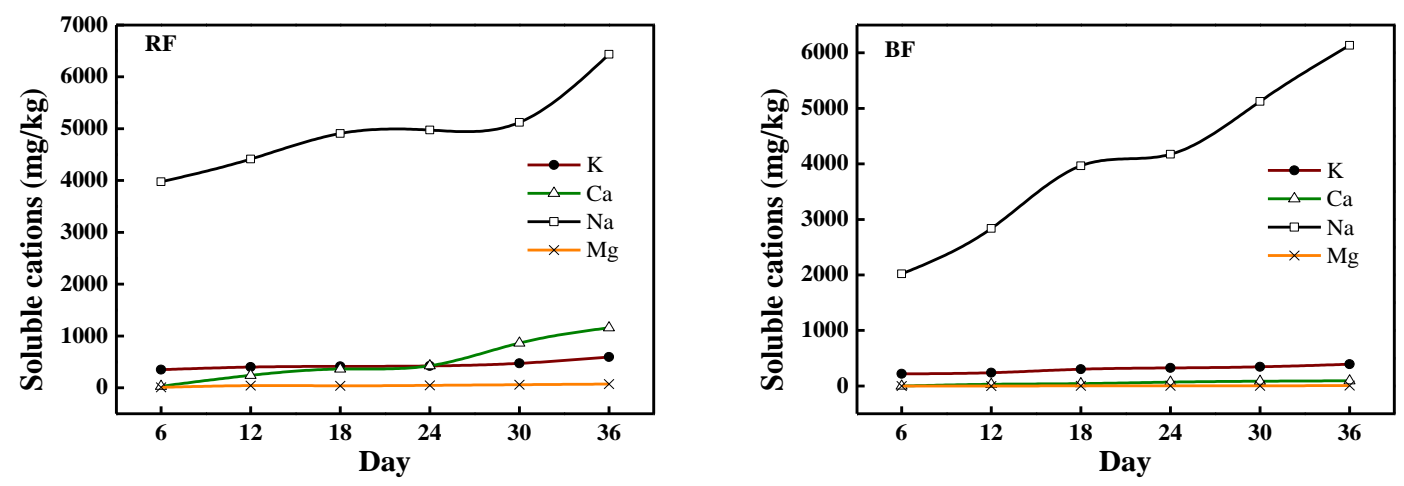
325 Na K-edge X-ray absorption near edge structure (XANES) spectra of bauxite residue 326 has two prominent absorption peaks $a$ and $b$, near 1068.2 and $1072.0 \mathrm{eV}$ (quoted to $327 \pm 0.2 \mathrm{eV}$ ) (Figure 6), and the peak positions determine the coordination structure of $\mathrm{Na}$ in bauxite residue. XANES analysis of $\mathrm{Na} \mathrm{K}$-edge indicated that two prominent 329 absorption peaks $a$ and $b$ from RF and BF, were almost uniform and similar to CK. In 330 this study, the local ordering around $\mathrm{Na}$ and the chemical morphology of calcium nephrite $\left(\mathrm{Na}_{8} \mathrm{Al}_{6} \mathrm{Si}_{6} \mathrm{O}_{24}\left(\mathrm{CO}_{3}\right)\left(\mathrm{H}_{2} \mathrm{O}\right)_{2}\right)$, and sodium quadrate $\left(\mathrm{Na}_{8} \mathrm{Al}_{6} \mathrm{Si}_{6} \mathrm{O}_{24} \mathrm{Cl}_{2}\right)$, did not change in the residues. The effect of $P$. oxalicum combined with pretreatment biomass 333 widened the main spectral peaks in the residue, and the displacement of peak $a$ to the high energy position was about $0.1-0.3 \mathrm{eV}$. Absorption peaks of RF and BF in residues was consistent with $\mathrm{CK}$, proving that the two treatments did not transform its chemical speciation. The normalized strength of bauxite residue under the action of $P$. oxalicum 337 was higher than that of the original bauxite residue, which is similar to the result of Kong directly treating bauxite residue with organic acids (Kong et al., 2017). 


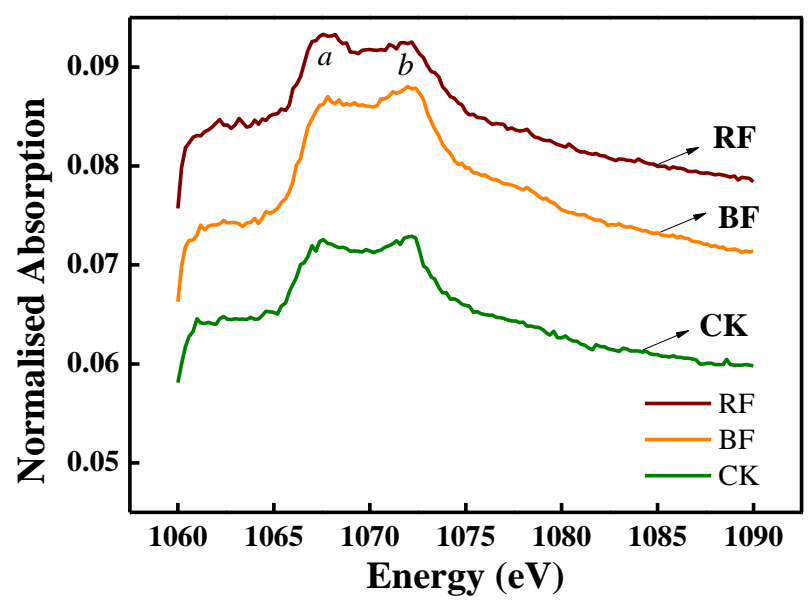

340 Figure 6 Normalized Na K-edge XANES spectra collected from bauxite residue, transformed residues by different methods

\section{Conclusions}

This work presents evidence for the bioremediation of bauxite residue using pretreatment biomass as a carbon source, in order to reduce its $\mathrm{pH}$ and $\mathrm{EC}$, increase cellulase and urease activity, and attempt to change the physicochemical properties of

347 bauxite residue. The biomass after steam explosion pretreatment was found to 348 significantly promote a decline in medium $\mathrm{pH}$ owing to acid production by $P$. oxalicum.

349 Organic acids metabolized by microbes in the biomass medium was consistent with the 350 glucose medium, including oxalic acid, formic acid and acetic acid. P. oxalicum may 351 also stimulate cellulase and urease activity in bauxite residue. In addition, inoculation 352 of the functional fungus with the addition of biomass significantly reduced the 353 alkalinity of bauxite residue, while EC increased with time, probably due to the 
dissolution of basic ions. It was also found that the metabolic process of the fungus could increase $\mathrm{Na}^{+}$. Absorption peaks of different treatments in residues was almost uniform and similar, proving that the microbe and biomass did not transform its chemical speciation. $P$. oxalicum is an important fungus in neutralizing alkalinity of bauxite residue by producing organic acids, and bioremediation may be considered as a promising way forward for the effective restoration on bauxite residue disposal areas.

(1) 

As(V)/Fe(III) from a Realgar Tailing Mine Soil. GEOMICROBIOL J 35:555-563.

4. Courtney R, Harrington T, Byrne KA. 2013. Indicators of soil formation in restored bauxite residues. ECOL ENG 58:63-68.

377

5. de Castro AM, de Albuquerque De Carvalho ML, Leite SGF, Pereira N. 2010. Cellulases from Penicillium funiculosum: production, properties and application to cellulose hydrolysis. J IND MICROBIOL BIOT 37:151-158.

6. Du J, Cao Y, Liu G, Zhao J, Li X, Qu Y. 2017. Identifying and overcoming the effect of mass transfer limitation on decreased yield in enzymatic hydrolysis of lignocellulose at high solid concentrations. BIORESOURCE TECHNOL 229:8895.

7. Gong M, Du P, Liu X, Zhu C. 2014. Transformation of inorganic P fractions of soil and plant growth promotion by phosphate-solubilizing ability of Penicillium oxalicum I1. J MICROBIOL 52:1012-1019.

8. Gräfe M, Klauber C. 2011. Bauxite residue issues: IV. Old obstacles and new pathways for in situ residue bioremediation. HYDROMETALLURGY 108:46-59.

9. Haghighi Mood S, Hossein Golfeshan A, Tabatabaei M, Salehi Jouzani G, Najafi GH, Gholami M, Ardjmand M. 2013. Lignocellulosic biomass to bioethanol, a comprehensive review with a focus on pretreatment. Renewable and Sustainable Energy Reviews 27:77-93.

10. Jones BEH, Haynes RJ. 2011. Bauxite Processing Residue: A Critical Review of Its Formation, Properties, Storage, and Revegetation. CRIT REV ENV SCI TEC 
11. Kaur A, Capalash N, Sharma P. 2019. Communication mechanisms in extremophiles: Exploring their existence and industrial applications. MICROBIOL RES 221:15-27.

12. Khaitan S, Dzombak DA, Lowry GV. 2009. Chemistry of the Acid Neutralization Capacity of Bauxite Residue. ENVIRON ENG SCI 26:873-881. HAZARD MATER 324:382-390.

14. Kong X, Tian T, Xue S, Hartley W, Huang L, Wu C, Li C. 2018. Development of alkaline electrochemical characteristics demonstrates soil formation in bauxite residue undergoing natural rehabilitation. LAND DEGRAD DEV 29:58-67.

15. Krishna P, Reddy MS, Patnaik SK. 2005. Aspergillus Tubingensis Reduces the $\mathrm{pH}$ of the Bauxite Residue (Red Mud) Amended Soils. Water, Air, and Soil Pollution 167:201-209.

16. Kumar P, Barrett DM, Delwiche MJ, Stroeve P. 2009. Methods for Pretreatment of Lignocellulosic Biomass for Efficient Hydrolysis and Biofuel Production. IND ENG CHEM RES 48:3713-3729.

17. Li Z, Bai T, Dai L, Wang F, Tao J, Meng S, Hu Y, Wang S, Hu S. 2016. A study of organic acid production in contrasts between two phosphate solubilizing fungi: Penicillium oxalicum and Aspergillus niger. SCI REP-UK 6.

18. Liao J, Jiang J, Xue S, Qingyu C, Wu H, Manikandan R, Hartley W, Huang L. 
2018. A novel acid-producing fungus isolated from bauxite residue: the potential to reduce the alkalinity. GEOMICROBIOL J 35:840-847.

19. Liao J, Zhang Y, Cheng Q, Wu H, Zhu F, Xue S. 2019. Colonization of Penicillium oxalicum enhanced neutralization effects of microbial decomposition of organic matter in bauxite residue. J CENT SOUTH UNIV 26:331-342.

20. Macelroy RD. 1974. Some comments on the evolution of extremophiles. BIOSYSTEMS 6:74-75.

21. Mesbah NM, Wiegel J. 2012. Life under Multiple Extreme Conditions: Diversity and Physiology of the Halophilic Alkalithermophiles. APPL ENVIRON MICROB 78:4074-4082.

22. Nannipieri P, Giagnoni L, Renella G, Puglisi E, Ceccanti B, Masciandaro G, Fornasier F, Moscatelli MC, Marinari S. 2012. Soil enzymology: classical and molecular approaches. BIOL FERT SOILS 48:743-762.

23. Peng S, Cao Q, Qin Y, Li X, Liu G, Qu Y. 2017. An aldonolactonase AltA from Penicillium oxalicum mitigates the inhibition of $\beta$-glucosidase during lignocellulose biodegradation. APPL MICROBIOL BIOT 101:3627-3636.

24. Qin S, Hu C, Dong W. 2010. Nitrification results in underestimation of soil urease activity as determined by ammonium production rate. PEDOBIOLOGIA 53:401404.

25. Qu Y, Lian B. 2013. Bioleaching of rare earth and radioactive elements from red mud using Penicillium tricolor RM-10. BIORESOURCE TECHNOL 136:16-23.

26. Roberts DP, Chen S, Jiang H, Shi F, Fan B, Yin Z. 2015. Phosphate solubilization 
and promotion of maize growth by Penicillium oxalicum P4 and Aspergillus niger P85 in a calcareous soil. CAN J MICROBIOL 61:913-923.

27. Roscoe R, Vasconcellos CA, Furtini Neto AE, Guedes GAA, Fernandes LA. 2000. Urease activity and its relation to soil organic matter, microbial biomass nitrogen and urea-nitrogen assimilation by maize in a Brazilian oxisol under no-tillage and tillage systems. BIOL FERT SOILS 32:52-59.

28. Salomskiene J, Jonkuviene D, Macioniene I, Abraitiene A, Zeime J, Repeckiene J, Vaiciulyte-Funk L. 2019. Differences in the occurence and efficiency of antimicrobial compounds produced by lactic acid bacteria. EUR FOOD RES TECHNOL 245:569-579.

29. Santini TC, Kerr JL, Warren LA. 2015. Microbially-driven strategies for bioremediation of bauxite residue. J HAZARD MATER 293:131-157.

30. Santini TC, Malcolm LI, Tyson GW, Warren LA. 2016. pH and Organic Carbon Dose Rates Control Microbially Driven Bioremediation Efficacy in Alkaline Bauxite Residue. ENVIRON SCI TECHNOL 50:11164-11173.

31. Sayed AM, Hassan MHA, Alhadrami HA, Hassan HM, Goodfellow M, Rateb ME. 2020. Extreme environments: microbiology leading to specialized metabolites. J APPL MICROBIOL 128:630-657.

32. Tao N, Shi W, Liu Y, Huang S. 2011. Production of feed enzymes from citrus processing waste by solid-state fermentation with Eupenicillium javanicum. International Journal of Food Science \& Technology 46:1073-1079.

33. Tian T, Zhou J, Zhu F, Ye Y, Guo Y, Hartley W, Xue S. 2019. Effect of 
amendments on the leaching behavior of alkaline anions and metal ions in bauxite residue. J ENVIRON SCI-CHINA 85:74-81.

34. Wang Y, Wu X, Zhu Y, Yang X, Li Y. 2013. Determination of Secalonic Acid A residues. SCI TOTAL ENVIRON 663:216-226.

477 